\title{
HEALTHY FOR WHOM - CONSUMERS OR THE FOOD AND BEVERAGE INDUSTRY?
}

Arun Gupta ${ }^{1}$, Radha Holla ${ }^{2}$

${ }^{1}$ Central Coordinator BPNI, MD,World Breastfeeding Trends Initiative (WBTi) Global Secretariat, Regional Coordinator, IBFAN South Asia, Convener-Alliance Against Conflict of Interest(AACI), Nutrition Advocacy in Public Interest(NAPi)

${ }^{2}$ Independent researcher and member, Alliance Against Conflict of Interest

Email addresses:

AG: arun.ibfan@gmail.com

RH: holla.radha@gmail.com

\section{Abstract}

Malnutrition, both undernutrition and obesity, with its links to non-communicable diseases, is probably today's most important public health challenge. Two reports published this year in Lancet, the first being the EAT-Lancet Commission Report and the second being the Global Burden of Disease (GBD) Diet Collaborators Report, lay the blame for the increasing burden of NCDs on sub-optimal and unhealthy diets. This commentary focuses on the latter report. That report holds excess intake of sodium as the biggest risk factor, underplaying the role of sugar, trans fats and processed foods. The report is also silent on the part played by the food industry, especially their marketing practices. In this essay, we highlight the lack of clarity in the GBD report and question its conclusions.

\section{Conflict of Interest Statement}

Neither author has a conflict of interest. No support of any kind was received including financial support, from any person, institution or industry.

Keywords: GBD Diet Collaborators Report, Global Burden of Disease, NCDs, unhealthy diet, poor quality diet, junk food, food and beverage industry, sugar, sodium, EAT-Lancet Commission Report 


\section{Background}

Unhealthy diets, use of tobacco, harmful consumption of alcohol, air pollution and lack of physical activity have been recognized as leading causes of non-communicable diseases (NCDs) - cardiovascular disease, diabetes, cancer and chronic respiratory diseases, contributing to 71\% of all deaths globally (WHO, 2018). With regard to dietary factors, over the past two decades, WHO has set up commissions and task forces, held high level meetings and issued several guidelines to limit the consumption of unhealthy foods including the Global Strategy on Diet, Physical Activity and Health, Ending Childhood Obesity, Comprehensive Implementation Plan on Maternal, Infant and Young Child Nutrition setting six nutrition targets to be achieved by 2020. It also set up a Global Action Plan for the Prevention and Control of Non-Communicable Diseases 2013-2030, which comprises nine global voluntary targets for nations to achieve prevention and control of NCDs. This includes halting the rise in diabetes and obesity, and a $30 \%$ relative reduction in the intake of salt by 2025. In May 2018, the World Health Assembly approved the 13th General Programme of Work, which includes reducing salt/sodium intake and eliminating industrially produced trans fats from the food chain. In addition, WHO has also endorsed a set of recommendations on the marketing of foods and non-alcoholic beverages to children. Further, it identified a set of "Best Buys" to guide the development of national policies and action plans, which includes reduced salt intake in food, replacement of trans fat with polyunsaturated fat and public awareness through mass media. Over the same period, many member countries have made commitments to prevent and manage NCDs.

To meet these goals, WHO's Global Health Observatory and the Institute for Health Metrics and Evaluation (IHME) have been estimating the Global Burden of Disease (GBD) and identifying dietary risk factors that contribute to NCDs. IHME also evaluates the strategies used to address them to assist policymakers in allocating resources to improve the health of the people (IHME, undated). Earlier reports of the GBD have been criticized on several grounds, including lack of adequate reliable data from many parts of the world. However, since May 2018, WHO and IHME have been collaborating formally to improve estimates of the global burden of disease and risk factors (WHO, 2018).

The Lancet this year published two reports that linked the mounting incidence of NCDs to the low consumption of healthy foods. According to the first paper - EAT-Lancet Commission report (Willett, et al. (2019) entitled 'Food in the Anthropocene: the EAT-Lancet Commission on healthy diets from sustainable food system' (hereinafter called EAT-Lancet Report), published in January 2019, both NCDs and nutritional deficiencies are more prevalent in low- and middleincome countries (LMICs); in all categories of countries, the poor and disadvantaged bear the greater burden of these diseases and deficiencies The second paper, the GBD Diet Collaborators Report titled Health effects of dietary risks in 195 countries, 1990-2017: a systematic analysis for the Global Burden of Disease Study 2017 (Afshin et al., 2019) (hereinafter called the GBD report), published in April 2019, identifies 16 dietary risk factors for NCDs and attributes the highest risk to excessive consumption of sodium (GBD Diet Collaborators, 2019). In this commentary, the authors share their concerns regarding the credibility of this report. 


\section{Lack of data and poor quality data}

The GBD report is based on a re-analysis of data from 1990 to 2017. The GBD 2017 Disease and Injury Incidence and Prevalence Collaborators Report acknowledges the lack of adequate data from Central and South Sub-Saharan African, Oceania and the Caribbean regions. The GBD Causes of Death Collaborators report of 2016 admits that of the 199 countries participating in the GBD Study 2016, 27 countries, mostly from Africa and Oceania, had no data, and 43 countries, again mostly from Africa, Oceania, South Asia and Middle-East, had poor quality data (GBD Causes of Death Collaborators, 2017). Similarly, the earlier GBD reports of 2013 and 2010 recognize the lack of adequate data as an important limitation. Other gaps in data include the lack of nationally representative individual-level data on intake of key foods and nutrients in different regions of the world, of nutrient content of mixed dishes and of local food composition tables. As Victoria Fan puts it, "even the best recipes and best chefs in the world can't make a meal out of spoiled (or non-existent) ingredients" (Fan, 2013). The studies in the meta-analyses on the association between the dietary factors and mortality and disability-adjusted life years (DALYs) were conducted essentially on populations of European descent, as little or no data were available from most other regions of the world. Though the report claims that extrapolation of data was done to take this into account, the validity of such extrapolation is unclear. Given the uncertainty regarding the cause of death and the presence of co-morbidity and other confounding factors and the extrapolation of data from one population to other populations of the world, the risk potential attributed by the GBD 2017 Diet Collaborators Report to various dietary factors may not be accurate and may lead to incorrect prioritization of actions by countries.

\section{Lack of consistency}

The 16 dietary risk factors were selected based on meta-analysis of their relationships and selected endpoints; however, there appears to be a lack of consistency when assessing the different components of selected dietary factors. For example, the category of milk includes only non-fat, low-fat and full-fat milk, but not other products made with milk such as cheese and yoghurt. The category of whole grain includes not just bran, germ and endosperm in their natural proportion, but also processed foods like breakfast cereals, bread, rice, pasta, biscuits and muffins, many of which may contain unhealthy ingredients if they are industrially processed. Free sugar intake appears to be limited to consumption of sugar-sweetened beverages (SSBs). However, free sugars are consumed, not just as beverages, but in several forms - in tea and coffee, in home-made drinks such as lemonade, in desserts and as an ingredient of many dishes in various cuisines. This total intake of sugar does not appear to have been considered in assessing risks. This may have resulted in under-estimation of risks associated with these dietary factors.

\section{Heterogeneity in population at global, regional and national levels}

The report does not seem to consider heterogeneity in the world population as well as within regions and nations as an important factor in attribution of risk. For instance, Forouhi and Unwin (2019) point to the differences in overall summary estimates for the relationships between fish consumption and dietary omega-3 fatty acids and type 2 diabetes across different regions of the 
world. Thus, the conclusions of the study, particularly regarding the potential risk of the selected dietary factors DALYs attributed to them, may not apply to many parts of the world.

\section{Presence of confounders}

The health of a population or even of an individual is dependent on several other factors such as the socio-economic and physical environment they live in as well as the equitable or inequitable distribution of resources and services that reflect the policies of the governments and their ideological stance. Poverty, lack of access to potable water, and lack of access to affordable preventive and curative health services can determine levels of morbidity and mortality in a population. Further, there may be exposure to other risk factors. For example, as Guo et al (2018) point out, high total dairy intake is significantly more likely in those who smoke and have high intake of sugar, eggs and red meat. While we concede that eliminating the presence of confounders in an attempt to isolate individual factors and link them with specific diseases is currently not possible at the level of GBD data, we believe that excluding these factors from the assessment can lead to erroneous conclusions, and thus to erroneous prioritization of both diseases and actions to reduce or manage them.

The GBD report acknowledges that due to the lack of nationally representative data on diets and nutrients, the epidemiological evidence supporting a causal relationship between dietary risks and disease endpoints was less strong than evidence supporting the link between established risk factors and specific diseases, such as tobacco and high systolic blood pressure (GBD report, 2019). The need for authentic data for dietary and nutrient intakes as well as mortality and morbidity figures for diseases from all countries is clear if accurate conclusions are to be drawn.

Even national-level estimates are of limited value, as they often do not reflect differences among populations within the country. Effective action to prevent NCDs requires sub-national data, especially in large countries or those with large populations. There is an urgent need to generate sub-national data that exposes the dietary and nutrient intake and disease patterns of communities differentiated by geography, by income, by occupation, and by the status of marginalization. Such data, rather than generalized global data or even national data, are needed in the prioritization of disease, its contributory factors, actions to prevent and manage it, and resource allocation. A primary reason for the lack of data from many regions of the world, particularly from low-and middle-income countries (LMICs) is the dearth of funds to either conduct research or build research capacity in these countries. Health budgets in LMICs form a fraction of their national budgets. These countries are usually dependent upon funds received through official development assistance (ODA) or other external funding mechanisms for conducting research. WHO’s Global Observatory on Health Research and Development data from 2018 reveal the inequalities that exist in such funding (WHO, 2019). For instance, while only four high-income countries in Africa received such funding, Seychelles received almost eight times the average amount by other African countries, many of which are LMICs (WHO, 2019). Funding from other sources such as philanthropic organizations and industry can have serious conflicts of interest and skew the results of the research in favor of the funder's priorities or ideological preferences. 


\section{Shifting discussion away from ultra-processed foods}

Both the WHO and the EAT-Lancet Commission report identify trans-fats and excessive consumption of sodium (salt) and free sugars as important contributors to NCDs (WHO, 2018; EAT-Lancet Commission Report, 2019). Ultra-processed foods contain excessive quantities of these dietary risk factors (Monteiro et al, 2011; Steele et al, 2017) and in some populations are the largest contributors to total energy intake (Baraldi et al, 2018; Steele et al, 2017). Consuming ultra-processed foods has been shown to impact human health (Monteiro et al, 2011; Lawrence \& Baker, 2019; Rico-Campa et al, 2019).

Even as an increasing number of studies link ultra-processed foods containing high levels of sugar and trans-fat to NCDs, the GBD Report, which also identifies these as dietary risk factors, attributes the highest risk to sodium. The report states that sugar and trans fats were "towards the bottom in ranking of dietary risks for deaths and DALYs for most high-population countries" (GBD Diet Collaborators, 2019), thus shifting the focus of the discussion away from ultraprocessed foods and SSBs. We acknowledge that GBD's mandate was assessing the risk potential of single dietary factors; however, focusing on single nutrients as is done in most population studies, including those assessing the impact of ultra-processed foods, has drawbacks (Hu FB, 2002; Reedy et al, 2010).

WHO's 'Best Buys' seeks the elimination of trans fat from processed and ultra-processed foods and an intake of less $10 \%$ of total energy intake as sugar for both adults and children throughout the life-course; however, it suggests that the intake should optimally be less than $5 \%$ of the total energy intake (WHO, 2015). It further recommends restricted intakes of SSBs, which has resulted in some decrease in both consumption of these drinks (Colchero et al, 2017; Lee et al, 2015; as well as some limited reduction in obesity incidence (Bourke \& Veerman, 2018; Escobar \& Veerman, 2013). While there has been as yet no attempt to set a limit on the amount of free sugars added to ultra-processed foods, probably because earlier there was no technique to distinguish between natural sugars and added sugars, today, the technology of measuring carbon isotopes can identify added sugars (Jahren et al, 2006). This may in future aid in more effectively addressing added sugar by the $\&$ \& industry rather than only holding the consumer responsible for consuming excess sugars.

\section{Using industry's language}

The EAT-Lancet report identifies 'unhealthy diets' as the main contributor to NCDs. The GBD report avoids using the term 'unhealthy diets' and replaces it with 'poor dietary habits.' This avoidance puts the onus of choice of foods to eat on the consumer and moves the focus away from the aggressive marketing for unhealthy foods that displaces the consumption of healthy foods. This common strategy that highlights people's freedom to choose, has also been used by the tobacco and alcohol industries (Friedman et al, 2015; Cox et al, 2017) to swing attention away from their marketing practices and shift the onus for change completely onto the consumer. According to Magnusson (2010), several governments support the ideology of commercial freedom and individual responsibility. Magnusson quotes the erstwhile UK Prime Minister Tony Blair as saying: "Our public health problems are not, strictly speaking, public health questions at all. They are questions of individual lifestyle - obesity, smoking, alcohol abuse, diabetes, sexually transmitted disease. These are not epidemics in the epidemiological sense. They are the result of millions of individual decisions, at millions of points in time.” 
The use of the term 'poor dietary habits' also hides the compulsions that shape people's food choices and habits, especially the choices of the poor, who, according to the EAT-Lancet Commission report, are the most impacted by sub-optimal diets. These compulsions are caused by, among other things, the rise in the prices of fruits, vegetables, nuts and milk in many low-and middle-income countries, the shift towards monoculture farming, a reduction in agricultural diversity, increasing joblessness in several countries, and the growing availability of cheap processed foods.

The GBD authors' use of 'poor dietary habits' seems to be in keeping with the increasing use of language favoured by the f\&b industry in scientific documents and in governance. Debating three strategies to regulate the industry, Stuckler and Nestle cite the UK Health Minister as saying that "the food and drinks industry should be seen, not just as part of the problem, but part of the solution..." (Stuckler and Nestle, 2012). This argument was used as early as April 1999, at a meeting of CEOs of leading food companies where a vice president of Kraft suggested: "We are saying that the industry should make a sincere effort to be part of the solution.... And that by doing so, we can help to defuse the criticism that's building against us” (Moss, 2013). The audience included CEOs of Nestlé, Kraft and Nabisco, General Mills, Pillsbury, Procter \& Gamble, Coca-Cola and Mars.

Shifting attention away from a specific dietary factor to another factor or from nutrition to physical activity has also been a tried and tested strategy of the sugar industry. As studies in the late ' 50 s and early '60s were indicating that excessive sugar consumption was a factor contributing to heart diseases, John Hickson, a top sugar industry executive, discussed a plan with others in the industry to shift public opinion "through our research and information and legislative programs.... Then we can publish the data and refute our detractors" (O’Connor, 2017). Industry documents discovered at Harvard University, the Universities of Illinois and California, and other libraries attest to the success of this strategy; saturated fat was termed the villain in heart diseases and the role of sugar was ignored. Coca Cola provided financial and logistical support to the Global Energy Balance Network (which is not in existence anymore), which argued that lack of physical exercise rather than excessive consumption of calories leads to obesity. That this argument has been bought to a large extent is evident from the statement of the UK Health Minister: “An emphasis on prevention, physical activity and personal and corporate responsibility could, alongside unified Government action, make a big difference" (Stuckler \& Nestle, 2012).While it is true that physical activity is a vital component of any strategy to prevent obesity, research has shown that excessive consumption of food, especially high energy foods, is the chief reason for weight gain (Luke \& Cooper, 2013; Faik et al, 2017; Pontzer et al, 2012).

\section{Has the f\&b industry influenced the assessment of the risk potential of dietary factors?}

As mentioned earlier, one of IHME's tasks is to evaluate strategies to reduce NCDs (IHME, undated). The GBD report notes that strategies and recommendations related to regulating the f\&b industry and ultra-processed foods - taxation, front of packet labelling, regulating advertising and marketing practices, especially to children, planned school meals, and so on may be cost effective, for example, for sodium. But it goes on to say that on the whole, their effects have been far below the required levels and that there is "almost no evidence" on the 
impact of these interventions on several dietary factors. The report adds that "cost-effectiveness analyses of dietary interventions are generally based on a range of simplifying assumptions and do not take into account the reactions of consumers (eg, substitution effect), the food industry (e.g., food reformulations and pricing strategies), and other stakeholders in the real world (GBD Diet Collaborators 2019). Their advice is to focus on promoting healthy diets rather than diminishing unhealthy diets by restricting their production and marketing (GBD Diet Collaborators 2019). Incidentally, the EAT-Lancet report also recommends promoting healthy diets rather than preventing unhealthy diets (EAT-Lancet Commission, 2019). Concluding their report, the GBD Diet Collaborators recommend more collaborations, including with industry, and targeting multiple sectors without specifying either the conflict of interest problems involved or a method of managing them. The GBD report thus appears to be a deliberate attempt at misleading the public toward an approach involving conflicts of interest with the f\&b industry.

A possible reason for the GBD report's stance is influence from its funding. While the report does not include conflict of interest statements by its authors, in January 2017, IHME received a grant of US\$ 279 million from the Bill \& Melinda Gates Foundation (BMGF) (IHME history). BMGF is also the largest private funder of WHO. The Foundation has links with the f\&b industry. As of 2014, it had invested in companies like Archer Daniels Midland, Kraft, Mondelez International, Nestle and Unilever, Coca-Cola, and Pepsico (Global Justice Now, 2016). Though the Foundation divested its investment portfolio in McDonald's and Coca-Cola in December 2014, it has invested in Arcos Dorados Holdings, Inc., which is Latin America's largest operator of McDonald's franchises. It also continues to hold stock in Coca Cola FEMSA, the largest bottler of Coca Cola, with a presence in several countries. Gates' partner Warren Buffet, is the single largest investor in Coca-Cola. The top 15 holdings of Bill Gates at the end of March 2019 included Berkshire Hathaway (founded by Buffet) in first place, Coca-Cola FEMSA in eighth place and Arcos Dorados Holdings in $14^{\text {th }}$ place (Gurufocus, June 2019). The holding in CocaCola FEMSA pays the third highest dividend in the Gates portfolio (Intelligent Income, May 2019).

\section{Conclusions}

While the GBD report has done a creditable task in synthesizing thousands of reports on the links between dietary factors and NCDs from many parts of the world, several limitations cast doubts on their conclusions, which may have led to either overestimation or underestimation of the risk potential of selected factors. The report highlights the urgent need for quality data from all parts of the world to be able to assess potential risk more accurately. Though one of the tasks of IHME is to assess strategies and guidelines for preventing and managing NCDs, the report is silent on the need to deal with the $\mathrm{f} \& \mathrm{~b}$ industry. A possible reason for this stance could be the influence of funding from a source with potential conflicts of interest. 


\section{References}

Afshin, Ashkan, Patrick John Sur, Kairsten A. Fay, Leslie Cornaby, Giannina Ferrara, Joseph S. Salama, Erin C. Mullany et al. (2019). Health effects of dietary risks in 195 countries, 1990-2017: a systematic analysis for the Global Burden of Disease Study 2017. The Lancet 393(10184):1958-1972.

Amy Luke, Richard S Cooper (2013). Physical activity does not influence obesity risk: time to clarify the public health message. International Journal of Epidemiology 42(6):1831-1836 https://doi.org/10.1093/ije/dyt159

Baraldi LG, Martinez Steele E, Canella DS, Monteiro CA (2018). Consumption of ultraprocessed foods and associated sociodemographic factors in the USA between 2007 and 2012: evidence from a nationally representative cross-sectional study. BMJ Open 8:e020574. doi: 10.1136/bmjopen-2017-020574

Bourke EJ, Veerman JL (2018). The potential impact of taxing sugar drinks on health inequality in Indonesia. BMJ Global Health 3:e000923.

Cabrera Escobar MA, Veerman JL, Tollman SM, Bertram MY, Hofman KJ (2013). Evidence that a tax on sugar sweetened beverages reduces the obesity rate: a meta-analysis. BMC Public Health. 13:1072. https://doi.org/10.1186/1471-2458-13-1072

Colchero MA, Rivera-Dommarco J, Popkin BM, Ng SW (2017). In Mexico, evidence of sustained consumer response two years after implementing a sugar-sweetened beverage tax. Health Affairs 36(3):564-71. doi:10.1377/hlthaff.2016.1231

Cox, W. M., Klinger, E., \& Fadardi, J. S. (2017). Free will in addictive behaviors: A matter of definition. Addictive Behaviors Reports 5:94-103. doi: 10.1016/j.abrep.2017.03.001

Curtis M (2016). Gated Development: Is the Gates Foundation always a force for the good? Global Justice Now. Available at https://www.globaljustice.org.uk/sites/default/files/files/resources/gjn_gates_report_june_20 16_web_final_version_2.pdf

Faik, A, Vanderhulst, E, Rossem I, \& Devroey, D (2017). Influence of physical activity and interest for food and sciences versus weight disorders in children aged 8 to 18 years. Journal of Preventive Medicine and Hygiene 58(2):E105-E113.

Fan V (2013). Global Burden of Disease Estimates: Secret Recipes or Spoiled Ingredients? Center for Global Development. Published March 11, 2013. Available at https://www.cgdev.org/blog/global-burden-disease-estimates-secret-recipes-or-spoiledingredients

Forouhi NG, Unwin N (2019). Global diet and health: old questions, fresh evidence and new horizons. Lancet Comment 393(10184):1916-1918. https://doi.org/10.1016/S0140$\underline{6736(19) 30500-8}$ 
Friedman LC, Cheyne A, Givelber D, Gottlieb MA, Daynard RA (2015). Tobacco industry use of personal responsibility rhetoric in public relations and litigation: disguising freedom to blame as freedom of choice. Am J Public Health 105(2):250-260.

doi:10.2105/AJPH.2014.302226

GBD 2016 Causes of Death Collaborators. Global, regional, and national age-sex specific mortality for 264 causes of death, 1980-2016: a systematic analysis for the Global Burden of Disease Study 2016. The Lancet. Global Health Metrics 390(10100):1151-1210. https://doi.org/10.1016/S0140-6736(17)32152-9

GBD 2017 Disease and Injury Incidence and Prevalence Collaborators. Global, regional, and national incidence, prevalence, and years lived with disability for 354 diseases and injuries for 195 countries and territories, 1990-2017: a systematic analysis for the Global Burden of Disease Study 2017. The Lancet Global Health Metrics 392(10159):1789-1858. https://doi.org/10.1016/S0140-6736(18)32279-7 018

Gurufocus. Available at https://www.gurufocus.com/guru/bill+gates/currentportfolio/portfolio

Hu FB (2002). Dietary pattern analysis: a new direction in nutritional epidemiology. Curr Opin Lipidol 13(1):3-9. https://www.ncbi.nlm.nih.gov/pubmed/11790957?dopt=Abstract

IHME (about). Available at http://www.healthdata.org/about

IHME (history) Available at http://www.healthdata.org/about/history

Intelligent Income. Bill Gates; Dividend Portfolio. Available at https://www.simplysafedividends.com/intelligent-income/posts/44-bill-gates-dividendportfolio

Jahren AH, Saudek C, Yeung EH, Kao WH, Kraft RA, Caballero B (2006). An isotopic method for quantifying sweeteners derived from corn and sugar cane. Am J Clin Nutr 84(6):1380-4. DOI: 10.1093/ajcn/84.6.1380.

Jing Guo, Dougkas A, Elwood PC, Givens D (2018). Dairy Foods and Body Mass Index over 10-Year: Evidence from the Caerphilly Prospective Cohort Study. Nutrients 10:1515. doi:10.3390/nu10101515

Lawrence Mark A, Baker Phillip I (2019). Ultra-processed food and adverse health outcomes BMJ 365:12289. DOI: 10.1136/BMJ.12289

Lee MM, Falbe J, Schillinger D, Basu S, McCulloch CE, Madsen KA (2019). SugarSweetened Beverage Consumption 3 Years After the Berkeley, California, Sugar-Sweetened Beverage Tax. American Journal of Public Health 109:637-639. https://doi.org/10.2105/AJPH.2019.304971

Lim SS, Vos T, Flaxman AD, Danaei D, Shibuya K, Adair-Rohani H, et al. (2012) A comparative risk assessment of burden of disease and injury attributable to 67 risk factors and risk factor clusters in 21 regions, 1990-2010: a systematic analysis for the Global Burden of Disease Study 2010. The Lancet 380(9859):2224-2260.

https://doi.org/10.1016/S0140-6736(12)61766-8 
Magnusson RS (2010). Obesity prevention and personal responsibility: the case of front-ofpack food labelling in Australia. BMC Public Health 10:662. doi:10.1186/1471-2458-10-662

Michael Moss (2013). The Extraordinary Science of Addictive Junk Food. The New York Times, Feb. 20, 2013. https://www.nytimes.com/2013/02/24/magazine/the-extraordinaryscience-of-junk-food.html?searchResultPosition=1

Monteiro CA, Levy RB, Claro RM, De Castro IRR, Cannon G (2011). Increasing consumption of ultra-processed foods and likely impact on human health: evidence from Brazil. Public Health Nutrition 14(1):5-13. DOI: 10.1017/s1368980010003241

O'Connor A (2017). How the sugar industry shifted blame to fat. The New York Times. September 12, 2017. https://www.corporateaccountability.org/media/how-the-sugar-industryshifted-blame-to-fat/

Pontzer H, Raichlen DA, Wood BM, Mabulla AZP, Racette SB, Marlowe FW (2012). Hunter-Gatherer Energetics and Human Obesity. PLoS ONE 7(7):e40503. https://doi.org/10.1371/journal.pone.0040503

Reedy J, Wirfalt E, Flood A, Mitrou PN, Krebs-Smith SM, Kipnis V, Midthune D, Leitzmann M, Hollenbeck A, Schatzkin A, Subar AF (2010). Comparing 3 dietary pattern methods--cluster analysis, factor analysis, and index analysis--With colorectal cancer risk: The NIH-AARP Diet and Health Study. Am J Epidemiol 171(4):479-87. https://doi.org/10.1093/aje/kwp393

Rico-Campà, A., Martínez-González, M.A., Alvarez-Alvarez, I., de Deus Mendonça, R., de la Fuente-Arrillaga, C., Gómez-Donoso, C. and Bes-Rastrollo, M. (2019). Association between consumption of ultra-processed foods and all-0cause mortality: SUN prospective cohort study. British Medical Journal 365:I1949. DOI: 10.1136/bmj.11949.

Steele EM, Popkin BM, Swinburn B, Monteiro CA. The share of ultra-processed foods and the overall nutritional quality of diets in the US: evidence from a nationally representative cross-sectional study. BMJ Population Health Metrics 15(1):6.

https://doi.org/10.1186/s12963-017-0119-3

Stuckler D, Nestle M (2015). Big Food, Food Systems, and Global Health. PLoS Med 9(6):e1001242. doi: 10.1371/journal.pmed.1001242

Wang H, Chelsea AL, Coates MW, Meghan DM, Levitz CE, Schumacher AE, et al. (2014). Global, regional, and national levels of neonatal, infant, and under-5 mortality during 19902013: a systematic analysis for the Global Burden of Disease Study 2013. The Lancet 384(9947): 957-979. https://doi.org/10.1016/S0140-6736(14)60497-9

WHO (2015). Guideline: Sugars intake for adults and children. Available at https://apps.who.int/iris/bitstream/handle/10665/149782/9789241549028_eng.pdf;jsessionid =7D36AA29B9DFB37A3ECE23DD5AA0AEE2? sequence=1

WHO (2018). WHO and IHME collaborate to improve health data globally. Available at http://www.healthdata.org/news-release/who-and-ihme-collaborate-improve-health-dataglobally 
WHO (2018). Time to Deliver. Available at https://www.un.org/pga/73/event/prevention-ofnon-communicable-diseases/

WHO (2019). One year on, Global Observatory on Health R\&D identifies striking gaps and inequalities. Available at https://www.who.int/features/2018/health-research-anddevelopment/en/

Willet W, Rockstrom J, Loken B, Springmann M, Lang T, et al. (2019). Food in the Anthropocene - EAT-Lancet Commission on healthy diets from sustainable food systems. The Lancet 393(10170):447-492. DOI: https://doi.org/10.1016/S0140-6736(18)31788-4 